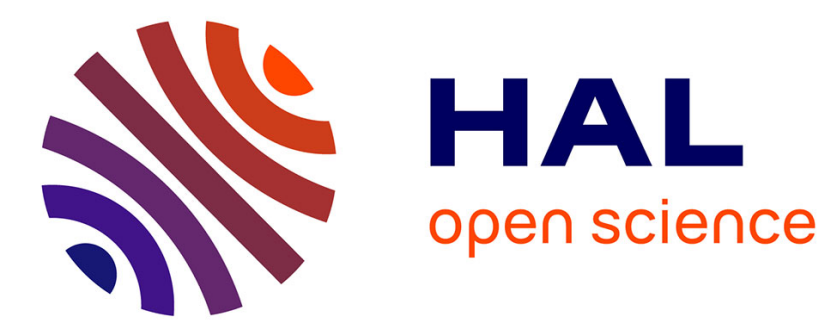

\title{
Numerical integration of an advanced Gurson model for shear loading: Application to the blanking process
}

Mohamed Achouri, Guénaël Germain, Philippe Dal Santo, Delphine Saidane

\section{To cite this version:}

Mohamed Achouri, Guénaël Germain, Philippe Dal Santo, Delphine Saidane. Numerical integration of an advanced Gurson model for shear loading: Application to the blanking process. Computational Materials Science, 2013, 72, pp.62-67. 10.1016/j.commatsci.2013.01.035 . hal-01068066

\section{HAL Id: hal-01068066 https://hal.science/hal-01068066}

Submitted on 4 May 2015

HAL is a multi-disciplinary open access archive for the deposit and dissemination of scientific research documents, whether they are published or not. The documents may come from teaching and research institutions in France or abroad, or from public or private research centers.
L'archive ouverte pluridisciplinaire HAL, est destinée au dépôt et à la diffusion de documents scientifiques de niveau recherche, publiés ou non, émanant des établissements d'enseignement et de recherche français ou étrangers, des laboratoires publics ou privés. 


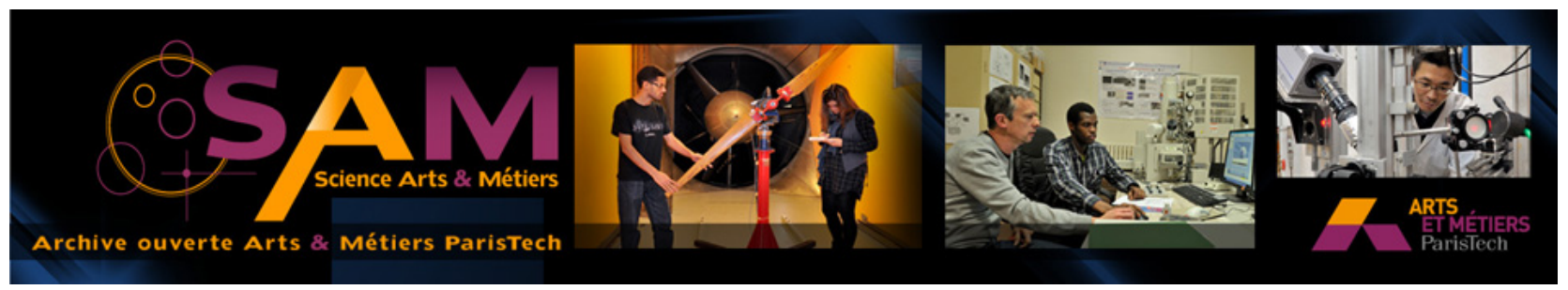

Science Arts \& Métiers (SAM)

is an open access repository that collects the work of Arts et Métiers ParisTech researchers and makes it freely available over the web where possible.

This is an author-deposited version published in: http://sam.ensam.eu

Handle ID: .http://hdl.handle.net/10985/8603

\section{To cite this version :}

Mohamed ACHOURI, Guénaël GERMAIN, Philippe DAL SANTO, Delphine SAIDANE - Numerical integration of an advanced Gurson model for shear loading: Application to the blanking process Computational Materials Science - Vol. 72, p.62-67 - 2013 


\title{
Numerical integration of an advanced Gurson model for shear loading: Application to the blanking process
}

\author{
Mohamed Achouri ${ }^{\mathrm{a}, \mathrm{b}, *}$, Guenael Germain ${ }^{\mathrm{a}}$, Philippe Dal Santo ${ }^{\mathrm{a}}$, Delphine Saidane ${ }^{\mathrm{b}}$ \\ ${ }^{a}$ LAMPA Laboratory (EA 1427), Arts et Métiers ParisTech, 2 Bd du Ronceray, 49000 Angers, France \\ ${ }^{\mathrm{b}}$ DEVILLE ASC, ZI de Beauregard, 49150 Baugé, France
}

Keywords:

Gurson ductile damage

Shear loading

Punching process

Numerical simulation

\begin{abstract}
A B S T R A C T
A new extension of the Gurson damage model has been proposed recently to predict ductile fracture under shear dominated loads. The aim of this work is to verify the ability of this approach to simulate, in an accurate way, the damage evolution in shearing processes. An implicit stress integration algorithm is then developed to implement the new model in a finite element code. The numerical procedure is checked through simulations of shear and uniaxial tension tests on a single elements. The extended Gurson damage model is tested and applied to the punching process to compare its predictive ability with the original approach. The obtained numerical results are in good agreement with experimental results of the punching process, showing better ductile fracture predictions compared to the original Gurson model.
\end{abstract}

\section{Introduction}

High-Strength Low-Alloy steels (HSLA) are widely used materials for the manufacture of automotive components, thanks to their high strength and good formability. In some forming processes such as blanking, localization of high level of plastic strain causes material damage followed by ductile fracture.

Studies have been conducted for the prediction of ductile failure in cases of high stress triaxiality. The fundamental theory has been developed by McClintock [1] and Rice and Tracey [2]. They studied the evolution of the growth of cylindrical and spherical voids in a ductile matrix. Gurson [3] proposed a model based on a micromechanical approach which describes the growth of spherical cavities and its influence on the material behavior. However, the Gurson model is inadequate for shear dominated loading conditions. The latter model was modified by Tvergaard and Needleman (GTN) [4] by adding a specific formulation for the ductile fracture of the material due to nucleation, growth and coalescence of spherical cavities. The GTN model has been improved to take into account the work hardening [5], the shape of the cavities [6-8] and the plastic anisotropy [9]. The major limitation of the original Gurson model is its inability to predict correctly the localization of the material damage and rupture under shear conditions exhibited in the punching process.

* Corresponding author at: LAMPA Laboratory (EA 1427), Arts et Métiers ParisTech, 2 bd du Ronceray, 49000 Angers, France. Tel.: +33 647397990.

E-mail address: mohamed.achouri@ensam.eu (M. Achouri).
Recent extensions of the Gurson model have been proposed by Nahshon and Hutchinson [10] to account for the effective damage accumulation due to the distortion of cavities and inter-cavity interacting in shear loading. Xue [11] has also developed a constitutive model where the damage accumulated in a solid material due to shear strain is treated in a phenomenological approach.

In this paper, recent extensions of Gurson model in terms of low stress triaxiality are detailed. Then the constitutive equations needed to implement the numerical algorithm of the model are developed. Numerical tests (uniaxial tensile and simple shear) on a single element are presented to verify the implemented formulation and to highlight the voids evolution (rotation and growth) due to shear loading. Finally, the simulation of the punching process of an axisymmetric component is performed in order to validate and calibrate the new damage parameter proposed in this modified model.

\section{Constitutive equations}

\subsection{Gurson model}

The Gurson theory [3] was the first physical approach which introduces a damage model coupled with the behavior of porous materials. The model is based on the assumption of a material made up of two main phases: matrix and inclusions. The approximation of the yield function $\Phi$ (Eq. (1)) depends on the spherical shape of the cavities in the matrix, in the form of: 
$\Phi=\left(\frac{q}{\sigma_{0}}\right)^{2}+2 f \cosh \left(-\frac{3 p}{2 \sigma_{0}}\right)-1-f^{2}=0$

where $\sigma_{0}$ is the flow stress of the material, $f$ represents the voids volume fraction of the material, $q=\sqrt{(3 / 2) \boldsymbol{s}: \boldsymbol{s}}$ is the von Mises equivalent stress with $s$ is the deviatoric part of the stress tensor and $p=-\operatorname{trace}(\boldsymbol{\sigma}) / 3$ is the hydrostatic stress.

\subsection{GTN model}

The yield function (Eq. (1)) was modified by Tvergaard and Needelman [4]. They introduce two constitutive coefficients $q_{1}$ and $q_{2}$ characterizing the interaction effects between the voids. The yield function then becomes:

$\Phi=\left(\frac{q}{\sigma_{0}}\right)^{2}+2 q_{1} f^{*} \cosh \left(-\frac{3 q_{2} p}{2 \sigma_{0}}\right)-\left(1+q_{1}^{2} f^{* 2}\right)=0$

If $q_{1}=q_{2}=1$ the GTN model coincides with the Gurson original model.

The effective void volume fraction, $f^{*}=f^{*}(f)$, was also introduced by Tvergaard and Needelman [4] to simulate the coalescence between voids. It is given by:

$f^{*}= \begin{cases}f & \text { si } f \leqslant f_{c} \\ f_{c}+\left(f-f_{c}\right) \frac{f_{u}-f_{c}}{f_{f}-f_{c}} & \text { si } f>f_{c}\end{cases}$

$f_{c}$ is the void volume fraction to trigger coalescence, $f_{u}=1 / q_{1}$ is the ultimate volume fraction and $f_{f}$ represents the void volume fraction at fracture.

The original evolution of the total volume fraction of voids due to plastic deformation is given by:

$\dot{f}=\dot{f}_{\text {growth }}+\dot{f}_{\text {nucleation }}$

The void growth rate is a function of the plastic strain rate and can be expressed by:

$\dot{f}_{\text {growth }}=(1-f) \operatorname{tr}\left(\dot{\boldsymbol{\varepsilon}}^{p}\right)$

$\dot{\boldsymbol{\varepsilon}}^{p}$ is the plastic strain rate tensor.

The second quantity accounting for the nucleation of cavities can be written as:

$\dot{f}_{\text {nucleation }}=A \dot{\bar{\varepsilon}}^{p}$

Nucleation of new cavities is taken to be governed by a normal distribution as suggested by Chu and Needleman [13], so that the coefficient $A$ in Eq. (6) takes the form:

$A= \begin{cases}\frac{f_{N}}{S_{N} \sqrt{2 \pi}} \exp \left[-\frac{1}{2}\left(\frac{\bar{\varepsilon}^{p}-\varepsilon_{N}}{S_{N}}\right)^{2}\right] & \text { for } p \geqslant 0 \\ 0 & \text { for } p<0\end{cases}$

$f_{N}$ is the quantity of voids to be nucleated per unit volume, $\varepsilon_{N}$ represents the nucleation strain and $S_{N}$ is corresponding standard deviation.

For low stress triaxiality $\eta=-p / q$, the Gurson model is unable to predict the growth rate of the voids. This issue is the subject of the present improvement of the model. Indeed, the modification introduces a phenomenological term that models the distortion and reorientation of voids dominated by shear stresses. This phenomenon was observed in previous experimental work performed on HSLA materials [12].

\subsection{Modified GTN model}

The new expression introduced by Nahshon and Hutchinson [10] is written as: $\dot{f}_{\text {shear }}=k_{w} \frac{f w(\boldsymbol{\sigma})}{q} \boldsymbol{s}: \dot{\boldsymbol{\varepsilon}}^{p}$

$w(\boldsymbol{\sigma})$ is a function of the stress state, characterized by the normalized third invariant of the deviatoric stress tensor $\left(\xi=27 J_{3} / 2 q^{3}\right)$. $k_{w}$ is a material parameter introducing the magnitude of damage growth rate in shear loading. The function $w(\boldsymbol{\sigma})$ is written as follows:

$w(\boldsymbol{\sigma})=1-(\xi)^{2}$

$J_{3}=\operatorname{det}(\mathbf{s})$ is the third invariant of the deviatoric stress tensor, $\boldsymbol{s}=\boldsymbol{\sigma}+p \boldsymbol{I}$.

$\boldsymbol{I}$ is the unit tensor.

After the addition of a new contribution in shear loading $\dot{f}_{\text {shear }}$, the evolution of the total void volume fraction becomes:

$\dot{f}=(1-f) \operatorname{tr}\left(\dot{\varepsilon}^{p}\right)+A \dot{\bar{\varepsilon}}^{p}+k_{w} \frac{f w(\sigma)}{q} \boldsymbol{s}: \dot{\boldsymbol{\varepsilon}}^{p}$

\section{Numerical implementation of the constitutive equations}

This section describes the implementation of the constitutive equations presented in the previous section. The modified Gurson model in shear loading is implemented in the finite element code ABAQUS/Explicit through a subroutine VUMAT [20]. The explicit time integration scheme is commonly used in strongly non-linear problems [14] such as the simulation of forming processes, especially for the treatment of damage and fracture problems in the punching process. In the developed user's material subroutine (VUMAT), the procedure includes two principal steps: an elastic prediction followed by a plastic correction where stresses are integrated using an implicit method in combination with the return mapping algorithm [15-17].

The total strain is split into elastic $\left(\varepsilon^{e}\right)$ and plastic $\left(\varepsilon^{p}\right)$ parts:

$\boldsymbol{\varepsilon}=\boldsymbol{\varepsilon}^{e}+\boldsymbol{\varepsilon}^{p}$

The plastic strain increment is further divided into spherical and deviatoric parts:

$$
\begin{aligned}
& \Delta \boldsymbol{\varepsilon}^{p}=\frac{1}{3} \Delta \varepsilon_{p} \boldsymbol{I}+\Delta \varepsilon_{q} \boldsymbol{n} \\
& \Delta \varepsilon_{p}=-\lambda \partial \Phi / \partial p \\
& \Delta \varepsilon_{q}=\lambda \partial \Phi / \partial q
\end{aligned}
$$

$\lambda$ is the plastic multiplier and $\boldsymbol{n}=\frac{3}{2 q} \boldsymbol{s}$ is the flow direction normal to the yield function boundary.

Eliminating $\lambda$ from Eqs. (13) and (14) leads to:

$\Delta \varepsilon_{p} \frac{\partial \Phi}{\partial q}+\Delta \varepsilon_{q} \frac{\partial \Phi}{\partial p}=0$

The equivalent plastic work principle is assumed, which allows obtaining the evolution function of matrix equivalent plastic strain:

$\Delta \bar{\varepsilon}^{p}=\frac{\boldsymbol{\sigma}: \Delta \varepsilon^{p}}{(1-f) \sigma_{0}}$

Substituting (Eq. (12)) into (Eq. (16)) gives:

$\Delta \bar{\varepsilon}^{p}=\frac{-p \Delta \varepsilon_{p}+q \Delta \varepsilon_{q}}{(1-f) \sigma_{0}}$

The void volume fraction $f$ and the equivalent plastic strain $\bar{\varepsilon}^{p}$ are considered as two scalar internal variables.

The main steps of the numerical algorithm are summarized below: 
- Step 1: initialize the variables $\left(\boldsymbol{\sigma}_{t}, \boldsymbol{\varepsilon}_{t}, f_{t}, \bar{\varepsilon}_{t}^{p}, \Delta \boldsymbol{\varepsilon}_{t+\Delta t}\right)$ at time $t=0$.

- Step 2: determine the elastic predictor by assuming that the strain increment is purely elastic:

$\boldsymbol{\sigma}_{t+\Delta t}^{\text {trial }}=\boldsymbol{\sigma}_{t}+\boldsymbol{C}: \Delta \boldsymbol{\varepsilon}_{t+\Delta t}$

where $\boldsymbol{C}$ is the fourth rank elastic tensor.

- Step 3: calculate the hydrostatic stress (Eq. (19)) and the equivalent von Mises stress (Eq. (20)):

$p_{t+\Delta t}^{\text {trial }}=\frac{1}{3} \sigma_{t+\Delta t}^{\text {trial }}: \mathbf{I}$

$q_{t+\Delta t}^{\text {trial }}=\sqrt{\frac{3}{2} \boldsymbol{s}_{t+\Delta t}^{\text {trial }}: \boldsymbol{s}_{t+\Delta t}^{\text {trial }}}$

- Step 4: calculate the yield function:

$\Phi_{t+\Delta t}^{\text {trial }}=\left(p_{t+\Delta t}^{\text {trial }}, q_{t+\Delta t}^{\text {trial }}, \bar{\varepsilon}_{t}^{p}, f_{t}\right)$

- If $\Phi_{t+\Delta t}^{\text {trial }} \leqslant 0$, hence the current state is elastic and $\boldsymbol{\sigma}_{t+\Delta t}=\boldsymbol{\sigma}_{t+\Delta t}^{\text {trial }}$, then go to step 6 .

- If $\Phi_{t+\Delta t}^{\text {trial }}>0$, the current state is plastic, then go to step 5 to calculate the plastic correction.

- Step 5: use the Newton-Raphson iterative method to perform a plastic correction. This algorithm allows the subroutine VUMAT to solve the following non-linear set of Eqs. (22) and (23).

$\Psi_{1}=\Delta \varepsilon_{p}^{(s+1)} \frac{\partial \Phi}{\partial q}+\Delta \varepsilon_{q}^{(s+1)} \frac{\partial \Phi}{\partial p}=0$

$\Psi_{2}=\Phi\left(p^{(s+1)}, q^{(s+1)}, \bar{\varepsilon}^{p(s+1)}, f^{(s+1)}\right)=0$

The flow rule and the consistency condition must be satisfied at the same time with the equivalent plastic work principle (Eq. (24)).

$\Delta \bar{\varepsilon}^{p(s+1)}=\frac{-p^{(s+1)} \Delta \varepsilon_{p}^{(s+1)}+q^{(s+1)} \Delta \varepsilon_{q}^{(s+1)}}{\left(1-f^{(s+1)}\right) \sigma_{0}}$

Note that the upper index $s$ is the iterative step counter value.

The algorithm stops iterations when the values of $\left|\Psi_{1}\right|$ and $\left|\Psi_{2}\right|$ are less than a specified tolerance $\mu_{t}=10 \mathrm{E}-07$.

- Step 6: update of variables:

$p=p^{\text {trial }}+K \Delta \varepsilon_{p}$

$q=q^{\text {trial }}-3 G \Delta \varepsilon_{q}$

$\boldsymbol{\sigma}=-p \boldsymbol{I}+\boldsymbol{s}$

$\Delta \bar{\varepsilon}^{p}=\frac{-p \Delta \varepsilon_{p}+q \Delta \varepsilon_{q}}{(1-f) \sigma_{0}}$

$\Delta f=(1-f) \Delta \varepsilon_{p}+A \Delta \bar{\varepsilon}^{p}+k_{w} w(\boldsymbol{\sigma}) \Delta \varepsilon_{q}$

$K=E / 3(1-2 v)$ is the bulk modulus and $G=E / 2(1+v)$ is the shear modulus. $E$ and $v$ are Young's modulus and Poisson's ratio, respectively.

Finally, the state variables are actualized in the form of:

$\bar{\varepsilon}^{p}=\bar{\varepsilon}_{(t)}^{p}+\Delta \bar{\varepsilon}^{p}$

$f=f_{(t)}+\Delta f$

- Step 7: end of the calculation step.

The numerical procedure goes on with a new time increment.

Now, the proposed procedure is applied to simple examples in order to test its validity and its predictive accuracy.

\section{Benchmark tests on single elements}

In this section, the model is checked using a series of numerical simulation. A single 8-node brick element with one integration point (C3D8R of ABAQUS) is used to simulate uniaxial tension and simple shear tests. The boundary conditions for each case are shown in Fig. 1. The initial size of each element edge is $1 \mathrm{~mm}$. The loading velocity $u_{3}$ for tension and $u_{2}$ for shearing are set to $0.01 \mathrm{~m} / \mathrm{s}$.

The material parameters chosen to simulate the test cases are:

- Material hardening low:

$\sigma_{0}=\sigma_{y}+K\left(\bar{\varepsilon}^{p}\right)^{n}$

In Eq. (32), the yield stress $\sigma_{y}=200 \mathrm{MPa}$, the material consistency $K=500 \mathrm{MPa}$ and the hardening exponent $n=0.1$.

- Damage parameters:

$q_{1}=1.5, q_{2}=1, f_{0}=0.005, \varepsilon_{N}=0.3, S_{N}=0.1, f_{N}=0.04$ and $k_{w}$ takes three values: 0,1 and 3 .

$f_{0}$ is the initial void volume fraction in the material.

\subsection{Uniaxial tension test}

The Fig. 2 shows the results for the uniaxial tensile test. The curves show the evolutions of the normalized axial stress $\sigma_{33} / \sigma_{y}$ and the void volume fraction $f$ as a function of axial strain $\varepsilon_{33}$. For a parameter value $k_{w}=0$, which coincides with the classical model GTN, the results provided by the implemented algorithm are perfectly superposed with the results given by the original GTN model included in the ABAQUS/Explicit code. This ABAQUS model is taken as reference for validating the test of the developed algorithm. It can be viewed that a variation of the value of $k_{w}$ has no influence on the evolution of the damage neither on the stress carrying capacity. In fact, in the case of the uniaxial tension $\xi=1$, then the parameter $w(\boldsymbol{\sigma})=1-(\xi)^{2}=0$.

\subsection{Simple shear test}

In the case of simple shear $w(\boldsymbol{\sigma})=1$. In order to simplify the analytical calculations, we assume that the nucleation of cavities is neglected and $f^{*}$ is taken to be equal to $f[10]$. Hence, the material fracture is only due to voids growth.

\subsubsection{Analytical developments}

For this loading condition, the equivalent plastic strain and equivalent plastic strain rate are defined by Eqs. (33) and (34), respectively:

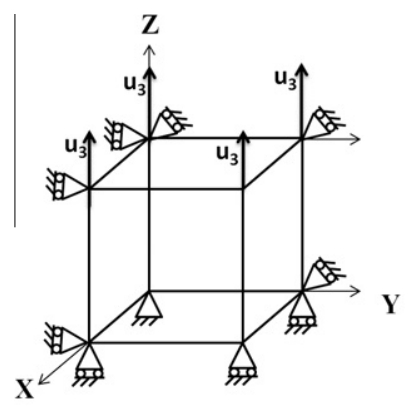

a

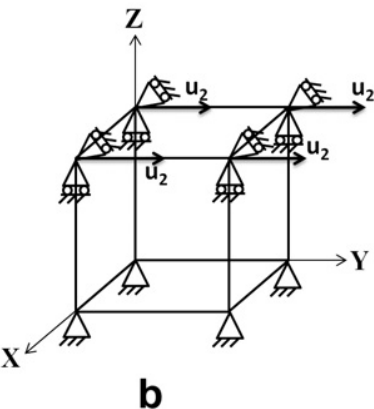

b
Fig. 1. Single element and boundary conditions for tests: (a) uniaxial tension and (b) simple shear 

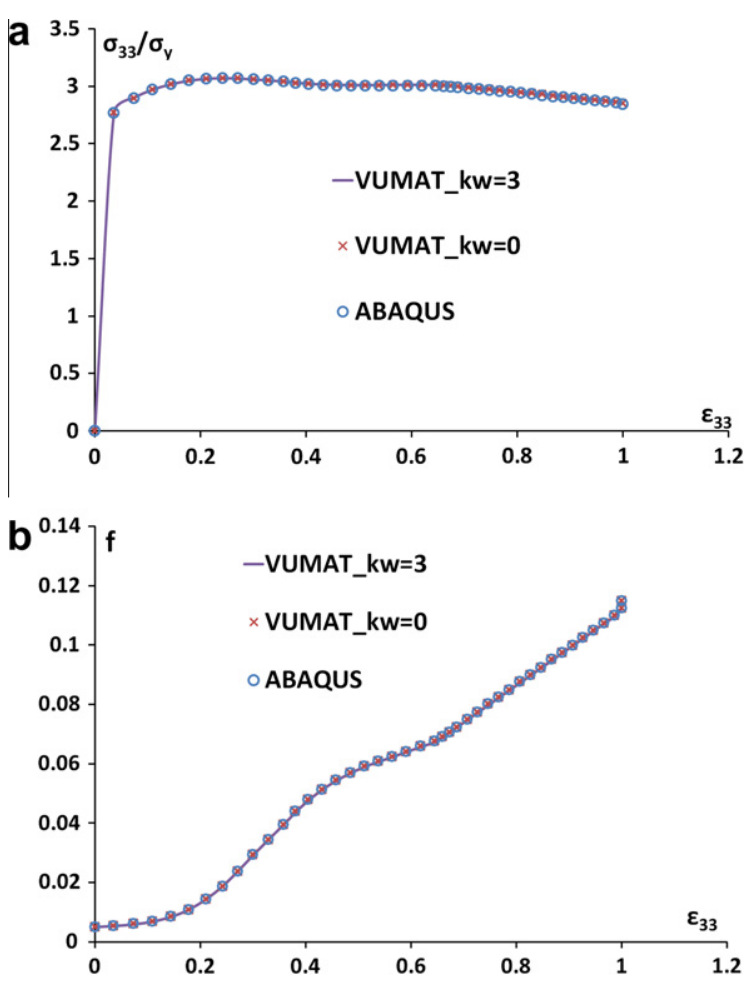

Fig. 2. Uniaxial tension test as a function of the axial strain: (a) normalized axial stress and (b) void volume fraction.

$\bar{\varepsilon}^{p}=\frac{2 \varepsilon_{23}^{p}}{\sqrt{3}}$

$\dot{\bar{\varepsilon}}^{p}=\frac{2 \dot{\varepsilon}_{23}^{p}}{\sqrt{3}}$

For $f<f_{c}$, the expression for the void evolution is:

$\dot{f}^{*}=\dot{f}=k_{w} f \dot{\bar{\varepsilon}}^{p}$

With these assumptions, an analytical formulation for the relative equivalent stress $q / \sigma_{y}$ can be obtained in view of comparing numerical and analytical results. For this purpose, integrating (Eq. (35)) leads to the void volume fraction expression:

$f=f_{0} \exp \left(k_{w} \bar{\varepsilon}^{p}\right)$

When $q_{1}=q_{2}=1$, the yield function equation (Eq. (2)) is simplified to:

$q=(1-f) \sigma_{0}$

Dividing the material hardening law by $\sigma_{y}$, the relationship between the normalized equivalent stress $q / \sigma_{y}$ and the effective strain $\bar{\varepsilon}^{p}$ is obtained in the final form by:

$\frac{q}{\sigma_{y}}=\left(1-f_{0} \exp \left(k_{w} \bar{\varepsilon}^{p}\right)\left(1+\frac{K}{\sigma_{y}}\left(\bar{\varepsilon}^{p}\right)^{n}\right)\right.$

\subsubsection{Numerical applications}

It is now possible to compare numerical results to analytical ones in case of a simple shear test. The results are shown in Fig. 3 where the variation of the normalized equivalent stress and the void volume fraction are plotted as a function of the equivalent plastic strain for different values of $k_{w}$. The good correlation between numerical predictions and analytical calculations confirms the validity of the modified model. An increase of $k_{w}$ value induces the reduction of the strain in the zone corresponding to damage localization. Fig. 3b illustrates the rapid growth of the
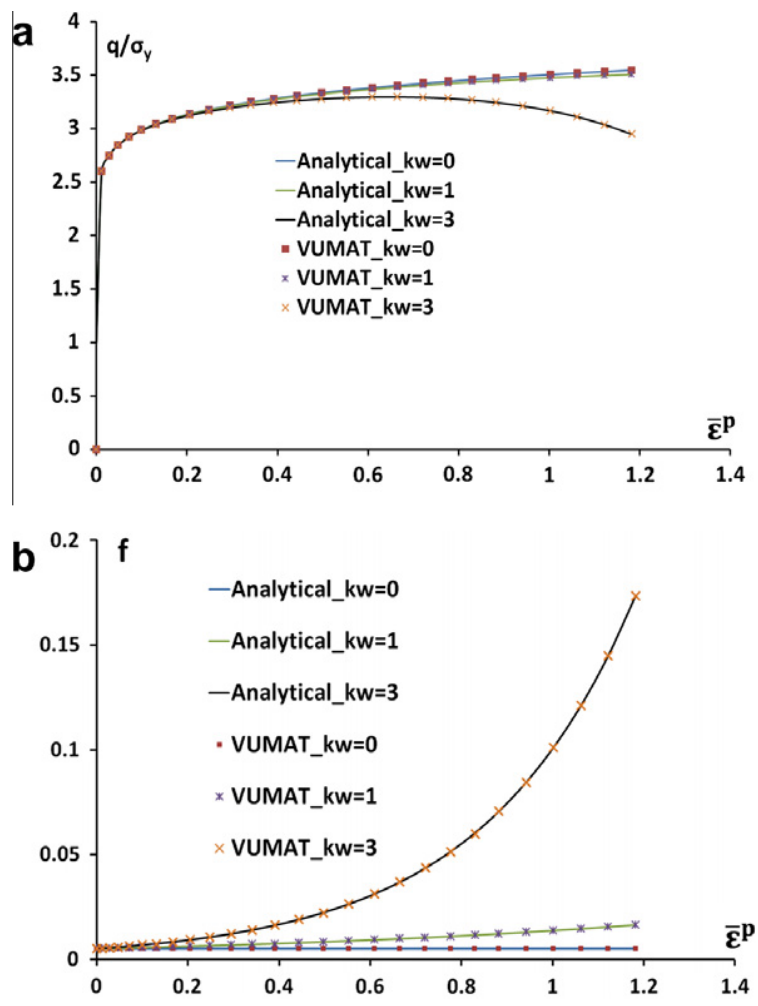

Fig. 3. Simple shear test as a function of the equivalent plastic strain: (a) normalized axial stress and (b) void volume fraction.

voids in case of shear dominated loading conditions $\left(k_{w}=1\right.$ and $k_{w}=3$ ). If $k_{w}=0$, the voids growth rate is equal to zero which coincides with the original GTN model.

\section{Application to the punching process}

Studies concerning material damage during the blanking process have been performed by many authors [19,22-24]. They have concluded that the GTN model cannot correctly predict the ductile fracture of the material during the blanking process. Indeed, the original approach does not take into account the damage growth under shear loading conditions. In order to validate the performance of the proposed implementation, numerical simulations of the punching process of sheet metal have been performed.

In order to determine the mechanical properties of the material, uniaxial tensile tests were carried out [18] on specimens of High Strength Low Alloy steel (see Table 1).

Table 1

Mechanical properties and damage parameters.

\begin{tabular}{lll}
\hline Notations & Parameters & Value \\
\hline$E$ & Young's modulus & $210 \mathrm{GPa}$ \\
$v$ & Poisson ratio & 0.3 \\
$\sigma_{y}$ & Yield stress & $570 \mathrm{MPa}$ \\
$n$ & Strain hardening exponent & 0.51 \\
$f_{0}$ & Initial voids volume fraction & 0.0 \\
$K$ & Strength index & $508 \mathrm{MPa}$ \\
$q_{1}$ & Gurson constant & 1.5 \\
$q_{2}$ & Gurson constant & 1 \\
$f_{N}$ & Void volume fraction to be nucleated & 0.04 \\
$\varepsilon_{N}$ & Mean nucleation strain & 0.3 \\
$S_{N}$ & Standard deviation on void nucleation & 0.1 \\
$f_{c}$ & Critical void volume fraction at coalescence & $10 \%$ \\
$f_{f}$ & Final void volume fraction at failure & $15 \%$ \\
$k_{w}$ & Shear coefficient & $0-3$ \\
\hline
\end{tabular}




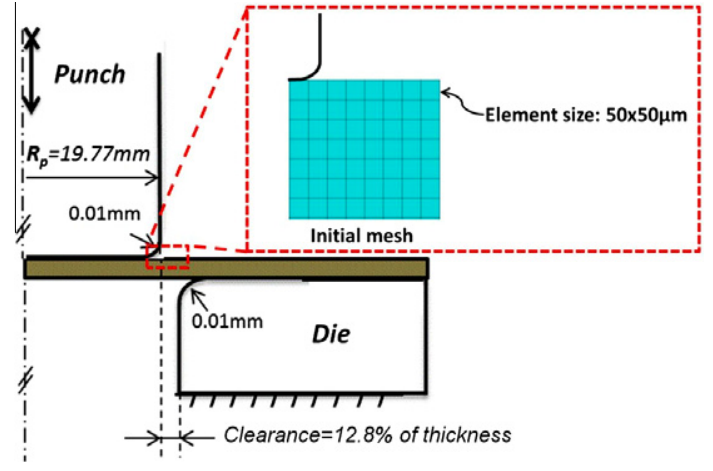

Fig. 4. Punching process: geometrical parameters of the tools and axisymmetric mesh.

The numerical results plotted in Fig. 5 corresponding to series of punching process, were compared to the experimental results. Experiments were carried out on strips of sheet metal with a thickness of $t=3.25 \mathrm{~mm}$. The punching device was mounted on a hydrostatic press with a capacity of $1000 \mathrm{kN}$. The punching force $(F)$ is measured by a Fine Guidance Sensor (reference: FN-2554) and the punching displacement $(d)$ is measured by a position sensor (BALLUFF-BTL 02F9), both connected to an acquisition system. The geometric parameters of the punching tools are shown in Fig. 4.

\subsection{Finite element model}

The finite element code ABAQUS/Explicit was used to simulate the punching operation in $2 \mathrm{D}$ using an axisymmetric assumption. The finite element mesh is illustrated in Fig. 4. The element size in the sheared region is set to $50 \times 50 \mu \mathrm{m}$. 4-node axisymmetric brick elements with reduced integration $(\mathrm{C} 4 \mathrm{X} 4 \mathrm{R})$ and hourglass section control were used. A Coulomb friction model is used to represent the contact between the sheet and the tools with a friction coefficient value equal to 0.1 which approximately corresponds to an industrial operation. The punch and the die are considered to be rigid bodies. The ALE (Arbitrary Lagrangian Euleurian [20]) technique is used to avoid element distortion in the sheared section. The material parameters given in Table 1 characterize the mechanical properties of the sheet metal under punching operation.

\subsection{Results and discussion}

\subsubsection{Identification of $k_{w}$ value}

A series of punching simulation were performed with several values of $k_{w}$ in order to calibrate the model in terms of the

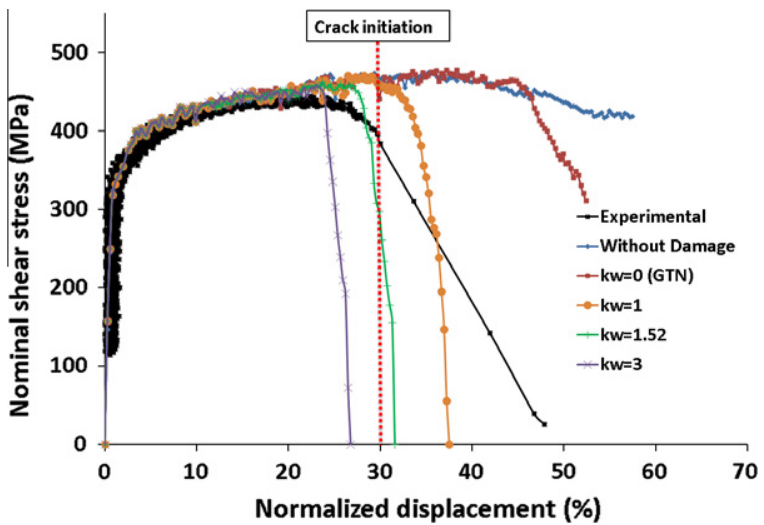

Fig. 5. Evolution of nominal shear stress versus normalized punch displacement.

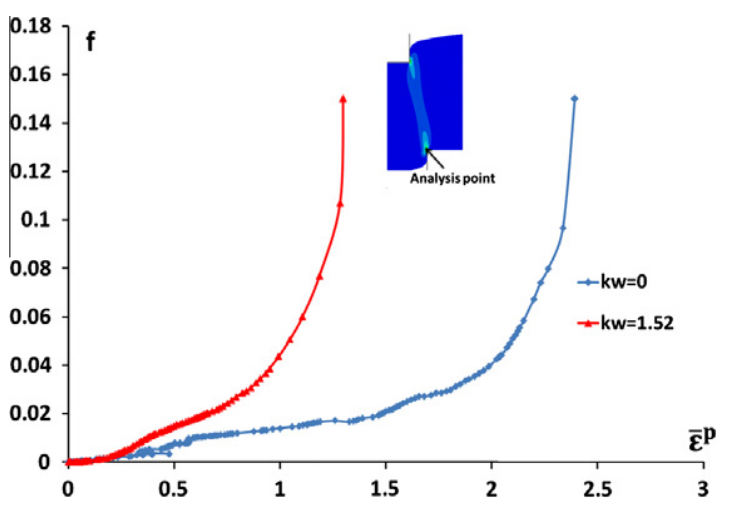

Fig. 6. Damage evolution at the fracture initiation point.

experimental data. Fig. 5 shows the evolution of the nominal shear stress defined by $\tau_{n}=F /\left(2 \pi R_{p} d\right)$, as a function of the normalized punch displacement $d / t$. The comparison between the experimental data and the numerical simulation results, allows the calibration of the $k_{w}$ value associated to the material fracture. It is commonly assumed that the fracture initiation starts with the decay of the nominal shear stress in the graph $\tau_{n}=f(d / t)$. Examining Fig. 5 , it is found that the value $k_{w}=1.52$ gives a good agreement between the experimental and numerical results. On the other hand, the results obtained for the value of $k_{w}=0$ confirms that the original GTN model is unable to capture shear damage initiation. However, the level of crack propagation rate is lower in the experimental case than in the numerical study with $k_{w}=1.52$. This is due to the contribution of the added damage term in the modified model which appears when the values $k_{w} \neq 0$.

\subsubsection{Damage evolution}

When values $k_{w} \neq 0$, it can be observed in Fig. 6 that the damage parameter $f^{*}$ grows sharply when the equivalent plastic strain reaches a value of about 1 . In other hand, a value $k_{w}=0$ is obviously inadequate to predict the material fracture initiation.

The microscopic analysis of the experimental shearing profile (Fig. 7) shows the three zones usually observed in the blanking operation: (a) rollover; (b) burnish and (c) fracture. The punch displacement associated with fracture initiation is calculated by the sum of rollover and burnish zone lengths [21]. In Fig. 7, the measured sum is equal to $1.19 \mathrm{~mm}$ corresponding to a normalized displacement of 33\% which is in good agreement with the value of $30 \%$ measured on the experimental and the predicted curves (with $\left.k_{w}=1.52\right)$ in Fig. 5 .

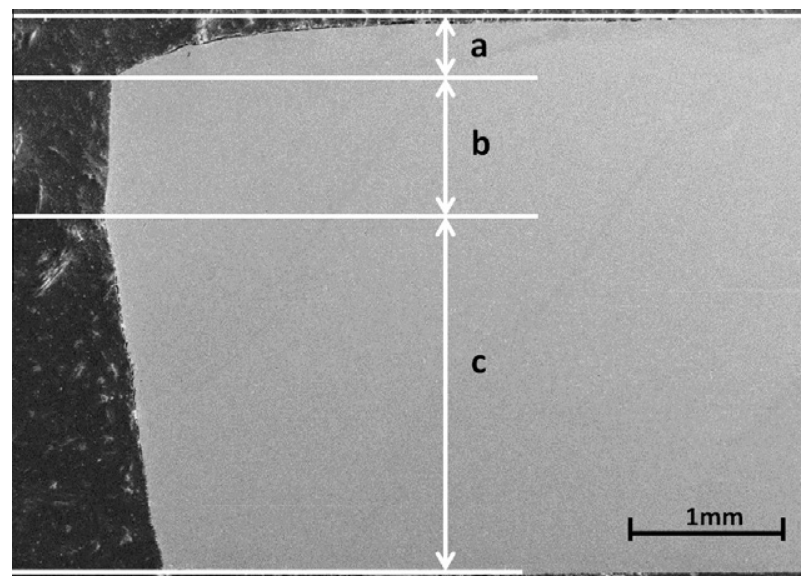

Fig. 7. Experimental shearing profile. 

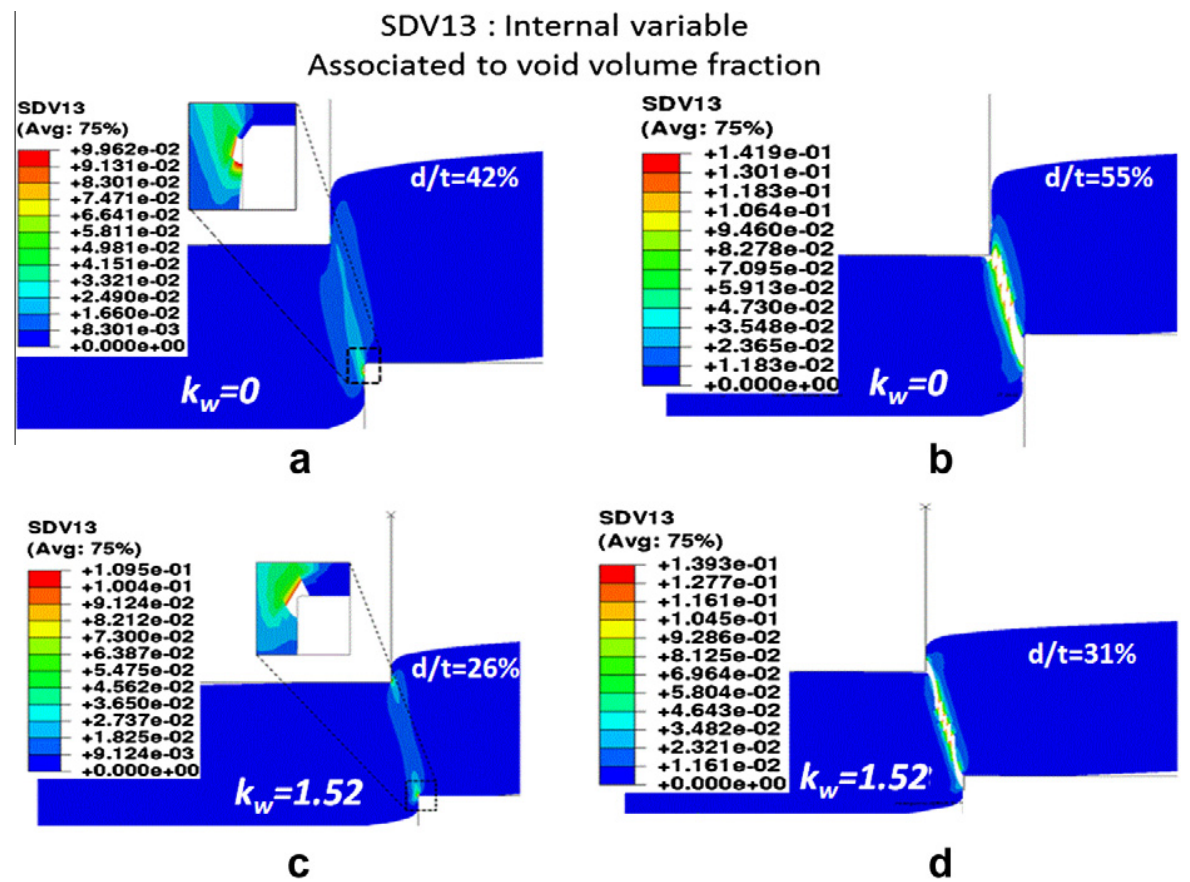

Fig. 8. Damage distribution on the numerical blanked profile: fracture initiation (a) and full fracture (b) for $k_{w}=0$, fracture initiation (c) and full fracture (d) for $k_{w}=1.52$.

The Fig. 8 illustrates the damage distribution predicted by the numerical analysis. It presents two phases: (i) fracture initiation (Fig. 8a and c); (ii) and full fracture of the material (Fig. 8 b and d). The fracture started at $42 \%$ of the punch penetration for $k_{w}=0$ and $26 \%$ for $k_{w}=1.52$. The value of penetration (26\%) at crack initiation for $k_{w}=1.52$ is slightly equal to the measured value on the associated numerical curve (beginning of the curve drop in Fig. 5). This can be explained by the new formulation of the model which accelerates the development of the void volume fraction value which models the material damage occurring during shearing processes, as shown in Fig. 6.

\section{Conclusion}

The aim of this paper was to implement and validate the new extended Gurson model proposed by Nahshon and Hutchinson, which addresses the problem of ductile shear fracture.

A new term was added to the original GTN model accounting for shear influence on the void evolution rate. The implementation of this new model is achieved using the finite element code ABAQUS/Explicit via the development of a user material subroutine VUMAT. An implicit algorithm procedure was proposed to integrate the above constitutive equations. Under simple shear loading conditions the new GTN model improvement is able to capture the shear damage localization. Finally, the punching process has been simulated to verify and study the influence of this improvement of the Gurson model. It is shown that the evolution of the normal shear stress versus the normalized displacement is well predicted compared to the classical Gurson model. The addition of a term responsible for the development of shear damage, results in the acceleration of the evolution of the void volume fraction which induces the early initiation and propagation of cracks in the shear zone between the die and the punch. Future works, will include the material anisotropy behavior and the influence of process parameters (clearance, punch and die radii...). In view of industrial applications, the calibration of the shear parameter $k_{w}$ will be done for different materials and several process configurations.

\section{Acknowledgement}

The authors would like to thank company Deville A.S.C. for its support during this investigation.

\section{References}

[1] F.A. McClintock, J. Appl. Mech. 35 (1968) 363-371.

[2] J.R. Rice, D.M. Tracey, J. Mech. Phys. Solids 17 (1969) 201-217.

[3] A.L. Gurson, J. Eng. Mater. Technol. 99 (1977) 2-15.

[4] V. Tvergaard, A. Needleman, Acta Metall. 32 (1984) 157-169.

[5] J.B. Leblond, G. Perrin, J. Devaux, Eur. J. Mech. A-Solids 14 (2) (1995) 499-527.

[6] M. Gologanu, J.B. Leblond, J. Devaux, J. Eng. Mater. Technol. 116 (3) (1994) 290-297.

[7] M. Garajeu, J.C. Michel, P. Suquet, Comput. Meth. Appl. Mech. Eng. 183 (2000) 223-246.

[8] T. Pardoen, J.W. Hutchinson, J. Mech. Phys. Solids 48 (2000) 2467-2512.

[9] A. Benzerga, J. Besson, A. Pineau, Acta Mater. 52 (2004) 4639-4650.

[10] K. Nahshon, J.W. Hutchinson, Eur. J. Mech. A-Solids 27 (2008) 1-17.

[11] L. Xue, Eng. Fract. Mech. 75 (2008) 3343-3366.

[12] M. Achouri, G. Germain, P. Dal Santo, S. Boude, J.L. Lebrun, D. Saidane, Key Eng. Mater. 473 (2011) 460-467.

[13] C.C. Chu, A. Needleman, J. Eng. Mater. Technol. 102 (3) (1980) 249-256.

[14] Chen Zengtao, J. Worswick Michael, A. Keith Pilkey, J. Lloyd David, J. Mech. Phys. Solids 53 (2005) 2692-2717.

[15] C. Betegon, J.J. del Coz, I. Penuelas, Comput. Meth. Appl. Mech. Eng. 195 (2006) 6146-6157.

[16] N. Aravas, Int. J. Numer. Meth. Eng. 24 (1987) 1395-1416.

[17] Z.L. Zhang, Comput. Meth. Appl. Mech. 121 (1995) 29-44.

[18] E. Gildemyn, Caractérisation des procédés de fabrication de pièces de sécurité automobile, Optimisation multi objectifs de la mise en forme, PhD thesis, Arts et Métiers ParisTech d'Angers, France, 2007.

[19] R. Hambli, Int. J. Mech. Sci. 43 (2001) 2769-2790.

[20] Abaqus, Reference Manuals, v6.10, Abaqus Inc., 2010.

[21] A. Bacha, D. Daniel, H. Klocker, J. Mater. Process. Technol. 210 (2010) 18851897.

[22] C. Husson, J.P.M. Correia, L. Daridon, S. Ahzi, J. Mater. Process. Technol. 199 (2008) 74-83.

[23] M. Rachik, J.M. Roelandt, A. Maillard, J. Mater. Process. Technol. 128 (2002) 256-265.

[24] H. Marouani, A. Ben Ismail, E. Hug, M. Rachik, Mater. Des. 30 (2009) 35663571 . 